\title{
INTERAÇÕES SINÉRGICAS E TRANSBORDAMENTO DO EFEITO MULTIPLICADOR DE PRODUÇÃO DAS GRANDES REGIÕES DO BRASIL
}

\author{
Umberto Antonio Sesso Filho ${ }^{\S}$ \\ Antonio Carlos Moretto ${ }^{\S}$ \\ Rossana Lott Rodrigues ${ }^{\S}$ \\ Joaquim José Martins Guilhoto
}

\begin{abstract}
RESUMO
Este artigo tem como objetivo estimar e analisar o nível das interações sinérgicas e o transbordamento do efeito multiplicador da produção setorial entre as cinco grandes regiões (Sul, Sudeste, Centro-oeste, Norte e Nordeste) e Restante do Brasil, utilizando sistemas inter-regionais de insumo-produto estimados para o ano de 1999. Os principais resultados foram: a) a produção da Região Norte é a mais dependente do fluxo de comércio entre esta e o restante do País (29\%), seguida da Região Nordeste (25\%), Centro-Oeste (24\%) e Sul (16\%); b) a região Sudeste é a menos dependente das vendas para o Restante do Brasil, as quais representavam $11 \%$; c) $13 \%$ da produção do Restante do Brasil depende do fluxo de insumos (bens e serviços) entre este e a Região Sudeste, o maior valor entre as regiões do País; d) no período de 1995/99, a dependência das regiões Sul, Sudeste e Centro-Oeste em relação ao Restante do Brasil diminuiu, ao passo que para as regiões Norte e Nordeste se elevou, notadamente para esta última, indicando maior interação comercial dessas últimas regiões relativamente ao Restante do Brasil; e) o maior efeito transbordamento ocorre nos setores das Regiões Centro-Oeste (média de 22\%) e Norte (média de 19\%); e f) o efeito transbordamento do Restante do Brasil para a Região Sudeste foi o maior entre as regiões (10\%).
\end{abstract}

Palavras-chave: insumo-produto, interações sinérgicas, economia regional.

\begin{abstract}
The objective of this paper is to estimate and analyze the level of synergetic interactions and overflow of production multiplier effect of the sectors between the five regions (South, Southwest, Center west, North and Northwest) and the Rest of Brazil, using estimated input-output inter-regional systems in the year 1999. The results are: a) the output of North Region is the most dependent of commerce between this and the Rest of Brazil (29\%) follow by the Northwest Region (25\%), Center West (24\%) and South (16\%); b) the Region Southwest is the less dependent of sells to the Rest of Brazil, those represented 11\%; c) $13 \%$ of the Rest of Brazil's output depended of the commerce of input (goods and services) between this and the Southwest Region, this is the biggest value between the Brazil Regions; d) in the period between 1995/99, the dependency of the Regions South, Southwest and Center West of the Rest of Brazil decreased, while the commerce between the Regions North and Northwest with the Rest of Brazil increased, e) the biggest overflow effect occurs in the sectors of Regions Center West (22\% average) and North (average 19\%); and f) the overflow effect of the Rest of Brazil to the Region Southwest was the biggest value, $10 \%$.
\end{abstract}

Key-words: input-output, synergetic interactions, regional economics.

JEL classification: R15.

$\S$ Professores do Departamento de Economia do Centro de Estudos Sociais Aplicados da Universidade Estadual de Londrina, Paraná.E-mails: umasesso@uel.br, acmoretto@uel.br, rlott@uel.br.

a Professor da Faculdade de Economia, Administração e Contabilidade da Universidade de São Paulo e do REAL University of Illinois.E-mail: guilhoto@usp.br.

Endereço para contato: Universidade Estadual de Londrina (UEL) - Departamento de Economia - Caixa Postal 6001 - CEP: 86051-990 - Londrina - Paraná - Fone: (43) 33714255.

Recebido em janeiro de 2005. Aceito em dezembro de 2005. 


\section{INTRODUÇÃO}

As economias estão cada vez mais interligadas umas às outras por meio do comércio de bens e serviços e do fluxo de capitais, situação que tende a se reforçar com o processo de globalização em curso. No Brasil, a economia brasileira inicia os anos 1990 sob os efeitos dos programas de liberalização comercial, que desde meados de 1980 vêm progressivamente sendo implantados. A competição mais acirrada resultante do processo de abertura econômica exige a reestruturação dos setores produtivos nacionais e regionais. Esta exigência encontra, no Brasil, regiões bastante díspares no que se refere à infra-estrutura, parque produtivo, capital humano, distribuição de renda e outros fatores. As diferenças regionais refletem-se nos dados da Tabela 1. A Região Sudeste possuía, em 1999, mais de dois quintos da produção nacional e o dobro do valor do PIB per capita da Região Norte e o triplo da Região Nordeste.

Tabela 1 - Estatísticas das grandes Regiões do Brasil (1999)

\begin{tabular}{lccccc}
\hline Macrorregiões & $\begin{array}{c}\text { PIB } \\
\text { (milhões R\$) }\end{array}$ & $\begin{array}{c}\text { PIB } \\
(\%)\end{array}$ & População & $\begin{array}{c}\text { População } \\
(\%)\end{array}$ & $\begin{array}{c}\text { PIB per capita } \\
(\mathrm{R} \$)\end{array}$ \\
\hline Norte & 42.867 & 4,45 & 12.682 .160 & 7,55 & 3.380 \\
Nordeste & 126.365 & 13,11 & $47.309,608$ & 28,18 & 2.671 \\
Sudeste & 561.468 & 58,25 & 71.591 .679 & 42,64 & 7.843 \\
Sul & 171.068 & 17,75 & 24.871 .190 & 14,81 & 6.878 \\
Centro-Oeste & 62.100 & 6,44 & 11.455 .101 & 6,82 & 5.421 \\
\hline Brasil & 963.868 & 100,00 & 167.909 .738 & 100,00 & 5.740 \\
\hline
\end{tabular}

Fonte: Instituto Brasileiro de Geografia e Estatística (IBGE), Contas Regionais do Brasil (2001).

Considerando que a auto-suficiência não é nem possível nem desejável do ponto de vista econômico, a integração entre as regiões brasileiras torna-se fator importante para o melhor desempenho do Brasil no atual cenário mundial. A maior interação entre diferentes regiões do País promove, concomitantemente, maiores efeitos sinérgicos e dependência econômica entre estruturas produtivas diferentes. $\mathrm{O}$ aumento da produção setorial em determinada região do Brasil tem impacto sobre a produção de diversas indústrias fora da localidade de origem, efeito denominado transbordamento do multiplicador de produção. Portanto, a mensuração das interações sinérgicas e do efeito transbordamento do multiplicador de produção torna-se importante fonte de informações para a análise do desenvolvimento regional e elaboração de políticas públicas, identificando as indústrias que apresentam maior dependência de insumos provenientes de outras regiões. Alguns estudos foram desenvolvidos para o Brasil para estimar os efeitos sinérgicos entre regiões. Como exemplos, podem se citados Guilhoto (1998), Guilhoto (1999), Guilhoto et al. (1999), Moretto (2000) e Guilhoto et al. (2001).

Por outro lado, o efeito transbordamento do multiplicador de produção não foi avaliado, com profundidade, para as grandes regiões brasileiras, recentemente. Assim, o objetivo geral do estudo é determinar o nível das interações sinérgicas e o transbordamento do efeito multiplicador da produção setorial entre as cinco grandes regiões (Sul, Sudeste, Centro-Oeste, Norte e Nordeste) e Restante do Brasil. Especificamente, pretende-se:

a) Estimar as interações sinérgicas entre as grandes regiões e o Restante do Brasil (RBR);

b) Estimar o transbordamento do multiplicador de produção setorial das grandes regiões e do Restante do Brasil; e

c) Comparar os indicadores econômicos (transbordamento e sinergia) entre as grandes regiões. 
Os resultados permitem identificar o nível de dependência (ou sinergia) das regiões em relação ao fluxo de comércio entre esta e Restante do País e as diferenças da estrutura produtiva que levam a diferentes graus de impacto da produção setorial da região sobre a produção de atividades fora da localidade original.

\section{Metodologia}

\subsection{Fonte dos dados}

Para a realização do estudo foi utilizada a estrutura setorial da matriz insumo-produto de 1999, do Brasil, estimada por Guilhoto e Sesso Filho (2005), e por meio do método do quociente locacional foram estimados os sistemas inter-regionais utilizando dados disponibilizados pelo Instituto Brasileiro de Geografia e Estatística (IBGE).

\subsection{Matriz de insumo-produto inter-regional}

O modelo inter-regional de insumo-produto, também chamado de "modelo Isard", devido à aplicação de Isard (1951), requer uma grande massa de dados, reais ou estimados, principalmente quanto às informações sobre fluxos intersetoriais e inter-regionais.

O Quadro 1 apresenta, de uma forma esquemática, as relações dentro de um sistema de insumo-produto inter-regional. Complementando o sistema regional, no sistema inter-regional há uma troca de relações entre as regiões, exportações e importações, que são expressas por meio do fluxo de bens que se destinam tanto ao consumo intermediário como à demanda final.

Quadro 1 - Relações de insumo-produto num sistema inter-regional

\begin{tabular}{|c|c|c|c|c|c|}
\hline & Setores - Região L & Setores - Região M & $\mathrm{L}$ & M & \\
\hline $\begin{array}{l}\text { Setores } \\
\text { Região } \\
\text { L }\end{array}$ & $\begin{array}{c}\text { Insumos Intermediários } \\
\text { LL }\end{array}$ & $\begin{array}{c}\text { Insumos Intermediários } \\
\text { LM }\end{array}$ & DF LL & DF LM & $\begin{array}{c}\text { Produção } \\
\text { Total } \\
\text { L }\end{array}$ \\
\hline \multirow[t]{5}{*}{$\begin{array}{l}\text { Setores } \\
\text { Região } \\
\text { M }\end{array}$} & $\begin{array}{c}\text { Insumos Intermediários } \\
\text { ML }\end{array}$ & $\begin{array}{l}\text { Insumos Intermediários } \\
\text { MM }\end{array}$ & DF ML & DF MM & $\begin{array}{c}\text { Produção } \\
\text { Total } \\
\text { M }\end{array}$ \\
\hline & $\begin{array}{l}\text { Importação do Restante do } \\
\text { Mundo (M) }\end{array}$ & $\begin{array}{l}\text { Importação do Restante do } \\
\text { Mundo (M) }\end{array}$ & M & M & M \\
\hline & $\begin{array}{l}\text { Impostos Indiretos Líquidos } \\
\text { (IIL) }\end{array}$ & Impostos Indiretos Líquidos (IIL) & IIL & IIL & IIL \\
\hline & Valor Adicionado & Valor Adicionado & & & \\
\hline & Produção Total Região L & Produção Total Região M & & & \\
\hline
\end{tabular}

De forma sintética, pode-se apresentar o modelo, a partir do exemplo hipotético dos fluxos intersetoriais e inter-regionais de bens para as regiões L e M, com 2 setores, como se segue: 
$Z_{i j}^{L L}$ - fluxo monetário do setor $i$ para o setor $j$ da região $\mathrm{L}$;

$Z_{i j}^{M L}$ - fluxo monetário do setor $i$ da região $\mathrm{M}$, para o setor $j$ da região $\mathrm{L}$.

$\mathrm{Na}$ forma de matriz, esses fluxos seriam representados por:

$$
Z=\left[\begin{array}{ll}
Z^{L L} & Z^{L M} \\
Z^{M L} & Z^{M M}
\end{array}\right]
$$

em que:

$Z^{L L}$ e $Z^{M M}$ representam matrizes dos fluxos monetários intra-regionais; e $Z^{L M}$ e $Z^{M L}$ representam matrizes dos fluxos monetários inter-regionais.

Considerando a equação de Leontief (1951 e 1986)

$$
X_{i}=z_{i 1}+z_{i 2}+\ldots+z_{i i}+z_{i n}+\ldots+Y_{i}
$$

em que $X_{i}$ indica o total da produção do setor $i, Z_{i n}$, o fluxo monetário do setor $i$ para o setor n, e $Y_{i}$, a demanda final por produtos do setor $i$, é possível aplicá-la conforme,

$$
X_{1}^{L}=z_{11}^{L L}+z_{12}^{L L}+\ldots+z_{11}^{L M}+z_{12}^{L M}+\ldots+Y_{1}^{L}
$$

em que $X_{1}^{L}$ é o total do bem 1 produzido na região $L$.

Considerando os coeficientes de insumo regional para L e M obtêm-se os coeficientes intraregionais:

$$
a_{i j}^{L L}=\frac{z_{i j}^{L L}}{X_{j}^{L}} \quad \Rightarrow \quad z_{i j}^{L L}=a_{i j}^{L L} \cdot X_{j}^{L}
$$

em que os $a_{i j}^{L L}$ podem ser definidos como coeficientes técnicos de produção, que representam quanto o setor $j$ da região L compra do setor $i$ da região L e

$$
a_{i j}^{M M}=\frac{z_{i j}^{M M}}{X_{j}^{M}} \quad \Rightarrow \quad z_{i j}^{M M}=a_{i j}^{M M} \cdot X_{j}^{M}
$$

em que os $a_{i j}^{M M}$ podem ser definidos como coeficientes técnicos de produção, que representam a quantidade que o setor $j$ da região $\mathrm{M}$ compra do setor $i$ da região $\mathrm{M}$.

E, por último, os coeficientes inter-regionais:

$$
a_{i j}^{M L}=\frac{z_{i j}^{M L}}{X_{j}^{L}} \quad \Rightarrow \quad z_{i j}^{M L}=a_{i j}^{M L} \cdot X_{j}^{L}
$$

em que os $a_{i j}^{M L}$ podem ser definidos como coeficientes técnicos de produção, que representam quanto o setor $j$ da região L compra do setor $i$ da região $\mathrm{M} \mathrm{e}$ 


$$
a_{i j}^{L M}=\frac{z_{i j}^{L M}}{X_{j}^{M}} \quad \Rightarrow \quad z_{i j}^{L M}=a_{i j}^{L M} \cdot X_{j}^{L}
$$

em que os $a_{i j}^{L M}$ correspondem aos coeficientes técnicos de produção, que representam a quantidade que o setor $j$ da região $\mathrm{M}$ compra do setor $i$ da região L.

Estes coeficientes podem ser substituídos em (3), obtendo-se:

$$
X_{1}^{L}=a_{11}^{L L} X_{1}^{L}+a_{12}^{L L} X_{2}^{L}+a_{11}^{L M} X_{1}^{M}+a_{12}^{L M} X_{2}^{M}+Y_{1}^{L}
$$

As produções para os demais setores são obtidas de forma similar.

Isolando $Y_{1}^{L}$ e colocando em evidência $X_{1}^{L}$, tem-se:

$$
\left(1-a_{11}^{L L}\right) X_{1}^{L}-a_{12}^{L L} X_{2}^{L}-a_{11}^{L M} X_{1}^{M}-a_{12}^{L M} X_{2}^{M}=Y_{1}^{L}
$$

As demais demandas finais podem ser obtidas similarmente. Portanto, de acordo com $A^{L L}=Z^{L L}\left(\hat{X}^{L}\right)^{-1}$, constrói-se a matriz $A^{L L}$ para os 2 setores, em que $A^{L L}$ representa a matriz de coeficientes técnicos intra-regionais de produção. Vale salientar que esta mesma formulação valeria para $A^{L M}, A^{M M}, A^{M L}$.

Definem-se agora as seguintes matrizes:

$$
\begin{aligned}
A & =\left[\begin{array}{ccc}
A^{L L} & \vdots & A^{L M} \\
\cdots & \cdots & \cdots \\
A^{M L} & \vdots & A^{M M}
\end{array}\right] \\
X & =\left[\begin{array}{c}
X^{L} \\
\cdots \\
X^{M}
\end{array}\right] \\
Y & =\left[\begin{array}{c}
Y^{L} \\
\cdots \\
Y^{M}
\end{array}\right]
\end{aligned}
$$

O sistema inter-regional completo de insumo-produto é representado por:

$$
(I-A) X=Y
$$

e as matrizes podem ser dispostas da seguinte forma:

$$
\left\{\left[\begin{array}{ccc}
I & \vdots & 0 \\
\cdots & \cdots & \cdots \\
0 & \vdots & I
\end{array}\right]-\left[\begin{array}{ccc}
A^{L L} & \vdots & A^{L M} \\
\ldots & \cdots & \ldots \\
A^{M L} & \vdots & A^{M M}
\end{array}\right]\right\}\left[\begin{array}{c}
X^{L} \\
\cdots \\
X^{M}
\end{array}\right]=\left[\begin{array}{c}
Y^{L} \\
\cdots \\
Y^{M}
\end{array}\right]
$$

Efetuando estas operações, obtêm-se os modelos básicos necessários à análise inter-regional proposta por Isard, e que resulta no sistema de Leontief inter-regional da forma:

$$
X=(I-A)^{-1} Y
$$




\subsection{Método do quociente locacional}

O método do quociente locacional constitui uma técnica bastante empregada em Economia Regional quando se deseja obter uma primeira aproximação do valor de determinadas variáveis para uma região qualquer, a partir do valor das mesmas variáveis obtidas por dados censitários em nível nacional. Segundo Souza (1997), a utilização dessa técnica supõe que a economia da região $j$ mantém a mesma estrutura da economia nacional em relação à indústria $i$.

Assim, o quociente locacional simples para o setor $i$ na região $R$, conforme Miller e Blair (1985), é definido como:

$$
L Q_{i}^{R}=\left[\frac{X_{i}^{R} / X^{R}}{X_{i}^{N} / X^{N}}\right]
$$

em que:

$X_{i}^{R}$ e $X^{R}$ denotam, respectivamente, os valores da produção do setor $i$ e da produção total na região $R$;

$X_{i}^{N}$ e $X^{N}$ denotam, respectivamente, os valores da produção do setor $i$ e da produção total nacional.

Quando os dados de produção de uma indústria, em uma dada região, não estão disponíveis, podem ser utilizadas outras medidas ou variáveis por setor, dentre as quais se destacam o emprego, a renda pessoal recebida, o valor adicionado, a demanda final etc. (Miller e Blair, 1985 e Round, 1983).

O presente método consiste em comparar a proporção do produto total da região R que é devida ao setor i com a proporção do produto total nacional advindo do setor i em nível nacional. $\mathrm{O}$ quociente locacional simples pode ser visto como uma medida da habilidade da indústria regional i para atender à demanda de outras indústrias e à demanda final da região. Se o valor do quociente for menor do que um, a indústria i é menos concentrada na região do que em nível nacional. Se for maior do que um, a indústria i é mais concentrada na região do que em nível nacional. Assim, para a linha i de uma tabela regional estimada, tem-se:

$$
a_{i j}^{R R}= \begin{cases}a_{i j}^{N}\left(L Q_{i}^{R}\right) & \text { se } L Q_{i}^{R}<1 \\ a_{i j}^{N} & \text { se } L Q_{i}^{R} \geq 1\end{cases}
$$

em que:

$a_{i j}^{R R}$ é o coeficiente de insumo regional;

$a_{i j}^{N}$ é o coeficiente técnico nacional. 


\subsection{Métodos de análise}

\subsubsection{Interações sinérgicas entre regiões}

Esta metodologia, desenvolvida por Sonis et al. (1997), permite classificar os tipos de interações sinérgicas entre regiões e possibilita examinar, por meio das interdependências internas e externas, dadas pelas ligações, a estrutura das relações comerciais entre duas regiões. Ela está baseada num sistema de insumo-produto partilhado e utiliza técnicas que produzem multiplicadores à esquerda e à direita da inversa de Leontief, dentro de um preestabelecido par de combinações hierárquicas dos subsistemas de ligações econômicas.

Considerando-se um sistema de insumo-produto representado pelo bloco de matrizes, A, de insumos diretos:

$$
A=\left[\begin{array}{ll}
A_{11} & A_{12} \\
A_{21} & A_{22}
\end{array}\right]
$$

em que $A_{11}$ e $A_{22}$ representam matrizes quadradas de insumos diretos dentro da primeira e segunda regiões, respectivamente, e $A_{12}$ e $A_{21}$ são matrizes retangulares dos insumos diretos adquiridos pela segunda região e vice versa, é possível interpretar a matriz A como um sistema de duas regiões em que a segunda região representa o restante da economia menos a primeira região.

A construção dos blocos de pares de combinações hierárquicas dos subsistemas de ligações intra e inter-regionais, num sistema de insumo-produto, é dada pelas matrizes $A_{11}, A_{12}, A_{21}$ e $A_{22}$, as quais correspondem a quatro blocos básicos de matrizes:

$$
A_{11}=\left[\begin{array}{cc}
A_{11} & 0 \\
0 & 0
\end{array}\right] ; \quad A_{12}=\left[\begin{array}{cc}
0 & A_{12} \\
0 & 0
\end{array}\right] ; \quad A_{21}=\left[\begin{array}{cc}
0 & 0 \\
A_{21} & 0
\end{array}\right] ; \quad A_{22}=\left[\begin{array}{cc}
0 & 0 \\
0 & A_{22}
\end{array}\right]
$$

A decomposição do bloco de matrizes (18) pode ser feita por meio da soma de dois blocos de matrizes, sendo cada um deles a soma dos blocos de matrizes de (19). Desta forma, pode ser apresentado um conjunto de multiplicadores regionais internos, derivados das matrizes inversas, as quais são blocos construídos das interações sinérgicas entre os subsistemas econômicos. O uso das diferentes interações sinérgicas possibilita analisar e mensurar como ocorrem as transações entre regiões. Assim, é possível verificar o quanto as relações de produção em uma dada região afetam a produção de outra região.

O Quadro 2 e a Figura 1 mostram, respectivamente, as interações sinérgicas e as combinações possíveis das partes da matriz $A_{1}$. A visão do sistema de hierarquias de ligações fornecerá novas interpretações das propriedades das estruturas que são reveladas. Além disso, os sistemas de insumoproduto partilhados podem diferenciar-se entre os vários tipos de dispersão (como 1, 2 e 3) e entre os vários modelos de interações inter-regionais (como 4 e 5). 
Quadro 2 - Ordenação das interações sinérgicas entre os subsistemas econômicos (continua)

Nivel 1 Descrição

Forma da Matriz $A_{1}$

Nível $2 L=L_{1}+\left(M_{L}-I\right) L_{1}=L_{1}+L_{1}\left(M_{R}-I\right)$

I. Hierarquia da região isolada versus o restante da economia

$$
A_{1}=\left[\begin{array}{cc}
A_{11} & 0 \\
0 & 0
\end{array}\right]
$$

$L=\left[\begin{array}{cc}B_{1} & 0 \\ 0 & I\end{array}\right]+\left[\begin{array}{cc}B_{1} A_{12} & 0 \\ 0 & I\end{array}\right] D_{2}\left[\begin{array}{cc}I & I \\ I & I-S_{2}\end{array}\right]\left[\begin{array}{cc}A_{21} B_{1} & 0 \\ 0 & I\end{array}\right]$

II. A ordem da hierarquia substituída das ligações inter-regionais da segunda região versus o subsistema triangular inferior

$$
A_{1}=\left[\begin{array}{cc}
0 & A_{12} \\
0 & 0
\end{array}\right]
$$

$L=\left[\begin{array}{cc}I & A_{12} \\ 0 & I\end{array}\right]+\left[\begin{array}{cc}D_{1} & 0 \\ 0 & D_{2}\end{array}\right]\left[\begin{array}{cc}I-S_{1} & A_{12} B_{2}-S_{1} A_{12} \\ A_{21} B_{1} & I-S_{2}\end{array}\right]$

III. A ordem da hierarquia substituída das ligações inter-regionais da primeira região versus o subsistema triangular superior.

$$
A_{1}=\left[\begin{array}{cc}
0 & 0 \\
A_{21} & 0
\end{array}\right]
$$

$L=\left[\begin{array}{cc}I & 0 \\ A_{21} & I\end{array}\right]+\left[\begin{array}{cc}D_{1} & 0 \\ 0 & D_{2}\end{array}\right]\left[\begin{array}{cc}I-S_{1} & A_{12} B_{2} \\ A_{21} B_{1}-S_{2} A_{21} & I-S_{2}\end{array}\right]$

IV. A ordem da hierarquia substituída das ligações para trás e para frente da primeira região versus o restante da economia

$$
A_{1}=\left[\begin{array}{cc}
0 & 0 \\
0 & A_{22}
\end{array}\right]
$$

$L=\left[\begin{array}{cc}I & 0 \\ 0 & B_{2}\end{array}\right]+\left[\begin{array}{cc}I & 0 \\ 0 & B_{2} A_{21}\end{array}\right] D_{1}\left[\begin{array}{cc}I-S_{1} & I \\ I & I\end{array}\right]\left[\begin{array}{cc}I & 0 \\ 0 & A_{12} B_{2}\end{array}\right]$

V. Hierarquia das ligações para frente da primeira e da segunda regiões

$$
A_{1}=\left[\begin{array}{cc}
A_{11} & A_{12} \\
0 & 0
\end{array}\right]
$$

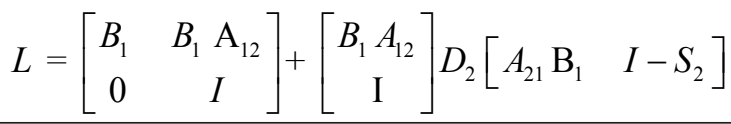

VI. Hierarquias das ligações para trás da primeira e segunda regiões

$$
A_{1}=\left[\begin{array}{ll}
A_{11} & 0 \\
A_{21} & 0
\end{array}\right]
$$

$L=\left[\begin{array}{cc}B_{1} & 0 \\ A_{21} B_{1} & I\end{array}\right]+\left[\begin{array}{c}B_{1} A_{12} \\ I-S_{2}\end{array}\right] D_{2}\left[\begin{array}{cc}A_{21} \mathrm{~B}_{1} & I\end{array}\right]$

VII. A hierarquia das relações intra versus inter-regionais

$$
A_{1}=\left[\begin{array}{cc}
A_{11} & 0 \\
0 & A_{22}
\end{array}\right]
$$

$L=\left[\begin{array}{cc}B_{1} & 0 \\ 0 & B_{2}\end{array}\right]+\left[\begin{array}{cc}D_{1} A_{12} B_{2} & 0 \\ 0 & D_{2} A_{21} B_{1}\end{array}\right]\left[\begin{array}{cc}A_{21} & I-A_{22} \\ I-A_{11} & A_{12}\end{array}\right]\left[\begin{array}{cc}B_{1} & 0 \\ 0 & B_{2}\end{array}\right]$ 
Quadro 2 - Ordenação das interações sinérgicas entre os subsistemas econômicos

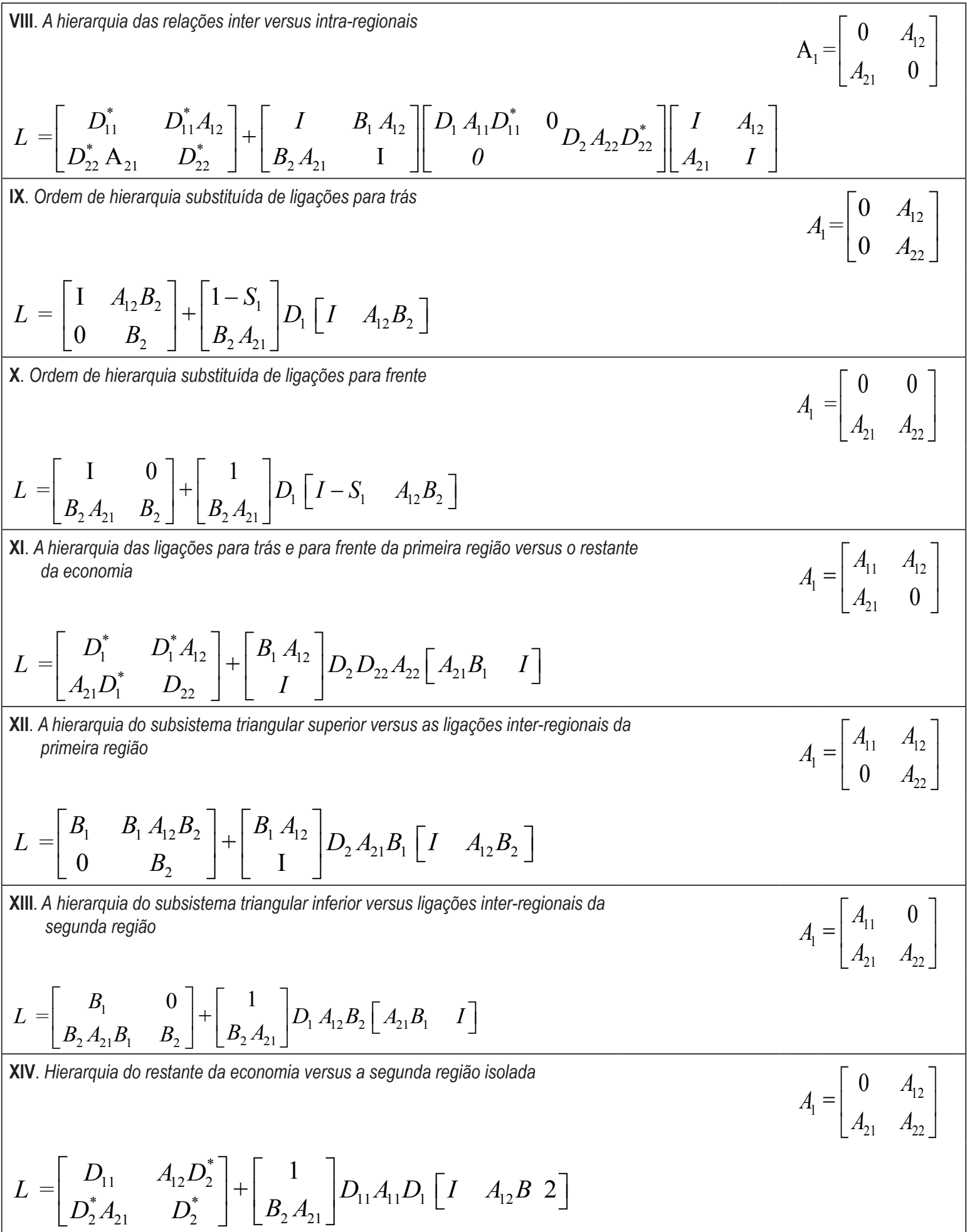

Fonte: Sonis et al. (1997). 
Cada entrada no Quadro 2 é composta de dois níveis. O primeiro descreve a estrutura e mostra a correspondente forma da matriz A1, enquanto o segundo mostra as decomposições aditivas da matriz bloco de Leontief. As matrizes B1, B2, S1, S2, D1, D2, D11, D22 representam um conjunto de multiplicadores regionais internos, derivados das matrizes inversas, as quais são blocos construídos das interações sinergéticas entre os subsistemas econômicos.

Assim, as matrizes $B_{1}=\left(I-A_{11}\right)^{-1}$ e $B_{2}=\left(I-A_{22}\right)^{-1}$ representam os multiplicadores internos de Miyazawa da primeira e segunda regiões, respectivamente, e mostram os efeitos de propagação interindustrial dentro de cada região, enquanto as matrizes $A_{21} B_{1}, B_{1} A_{12}, A_{12} B_{2}$ e $B_{2} A_{21}$ retratam os efeitos sobre a produção nas duas regiões.

As expressões $S_{1}=I-A_{11}-A_{12} B_{2} A_{21}$ e $S_{2}=I-A_{22}-A_{21} B_{1} A_{12}$ são, usualmente, referidas como os complementos de Schur. Delas pode-se derivar

$$
\left[\begin{array}{cc}
I-A_{11} & -A_{12} \\
-A_{21} & I-A_{11}
\end{array}\right]=\left[\begin{array}{cc}
I & D_{1} A_{12} B_{2} \\
0 & D_{2}
\end{array}\right]\left[\begin{array}{cc}
B_{1} & 0 \\
A_{21} B_{1} & I
\end{array}\right]
$$

em que (20) é referida por Sonis et al. (1997b) como a fórmula inversa de Schur-Banachiewicz e fornece as bases para a classificação das interações sinérgicas entre as ligações dos subsistemas econômicos.

As matrizes $D_{1}$ e $D_{2}$ dos complementos de Schur acima são referidas como as inversas de Schur para a primeira e segunda regiões, respectivamente. Elas representam a inversa de Leontief ampliada para uma região e revelam a influência econômica induzida da outra região, ou seja, as inversas de Schur representam os efeitos de propagação total na primeira e segunda regiões.

As matrizes de multiplicadores externos à esquerda e à direita da primeira e segunda regiões, $D_{11}^{L}, D_{11}^{R}, D_{22}^{L}$ e $D_{22}^{R}$, foram introduzidas por Miyazawa (1976). Os multiplicadores dessas matrizes são incorporados na decomposição multiplicativa das inversas de Schur, e representam os efeitos de propagação total na primeira e segunda regiões tanto quanto os produtos internos e externos da matriz regional de multiplicadores

A introdução das inversas de Schur abreviadas, $D_{11}, D_{22}$, e os multiplicadores internos induzidos à esquerda e à direita para a primeira e segunda regiões, $B_{1}^{L}, B_{1}^{R}, B_{2}^{L}$ e $B_{2}^{R}$, permitem obter a decomposição multiplicativa das inversas de Schur:

$$
D_{1}=B_{1}^{L} D_{11}=D_{11} B_{1}^{R} ; \quad D_{2}=B_{2}^{L} D_{22}=D_{22} B_{2}^{R}
$$

e suas correspondentes representações aditivas.

A fórmula para este grupo de multiplicadores pode ser obtida por meio dos blocos de matrizes:

$$
M=\left[\begin{array}{cc}
A_{11} & A_{12} \\
A_{21} & 0
\end{array}\right], \quad N=\left[\begin{array}{cc}
0 & A_{12} \\
A_{21} & A_{22}
\end{array}\right], \quad S=\left[\begin{array}{cc}
0 & A_{12} \\
A_{21} & 0
\end{array}\right]
$$

os quais representam as ligações para trás e para frente da primeira e segunda regiões bem como as relações inter-regionais de ambas as regiões.

A matriz $D_{22}=\left(I-A_{21} B_{1} A_{12}\right)^{-1}$ é interpretada como o multiplicador de renda inter-regional, enquanto $D_{22} A_{21} B_{1}$ refere-se à matriz do multiplicador de formação de renda. Além disso, a seguinte inversa de Schur

$$
D_{1}^{*}=\left(I-A_{11}-A_{12} A_{21}\right)^{-1}
$$


pode ser referida como a inversa de Leontief ampliada, e as inversas

$$
D_{11}^{* L}=\left(I-B_{1} A_{12} A_{21}\right)^{-1} ; \quad D_{11}^{* R}=\left(I-A_{12} A_{21} B_{1}\right)^{-1}
$$

são chamadas de matrizes de multiplicadores da inversa acrescentada à esquerda e à direita, as quais refletem os efeitos de mudanças endógenas nos gastos de consumo de cada grupo de renda.

Sonis et al. (1997a), Guilhoto et al. (1998) e Guilhoto et al. (1999) salientam que é possível sugerir uma tipologia de categorias que podem ser empregadas para melhor visualização dos 14 tipos de pares de combinações hierárquicas de ligações econômicas apresentados no Quadro 2 e na Figura 1. Assim, tem-se a seguinte caracterização:

1. tipo de ligação para trás (VI, IX): poder de dispersão;

2. tipo de ligação para frente $(\mathrm{V}, \mathrm{X})$ : sensibilidade de dispersão;

3. tipo de ligações intra e inter-regionais (VII, VIII): dispersão interna e externa;

4. estilo de interações de região isolada versus o restante da economia (I, XIV, IV, XI);

5. estilo de subsistema triangular versus as interações inter-regionais (II, XIII, III, XII).

A visão do sistema de hierarquias de ligações permitirá fornecer novas interpretações das propriedades das estruturas que são reveladas. Além disso, os sistemas de insumo-produto partilhados podem diferenciar-se entre os vários tipos de dispersão (como 1, 2 e 3) e entre os vários modelos de interações inter-regionais (como 4 e 5). Essencialmente, as 5 categorias e os 14 tipos de pares de combinações hierárquicas de ligações econômicas propiciam a oportunidade de escolher de acordo com as qualidades especiais das atividades de cada região e com o tipo de problema que se apresenta, evidenciando que as opções existem para as bases de uma tipologia de ligações econômicas apoiadas na estrutura hierárquica. $\mathrm{O}$ uso das diferentes interações sinérgicas possibilita analisar e mensurar como ocorrem as transações entre regiões. Assim, é possível verificar o quanto as relações de produção em uma dada região afetam a produção de outra região.

Figura 1 - Representação esquemática das formas possíveis da matriz A1 - o caso de duas regiões

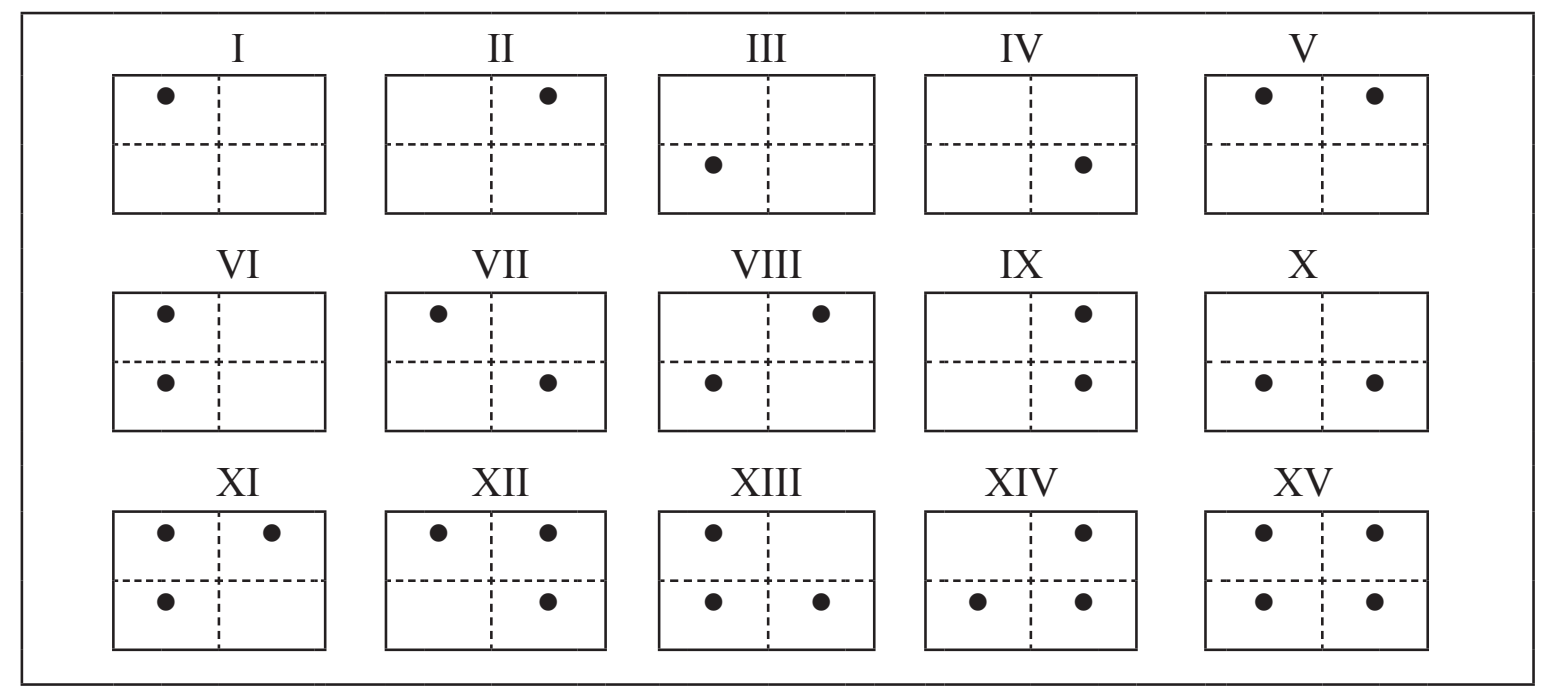

Fonte: Moretto (2000). 


\subsubsection{Efeito transbordamento do multiplicador de produção}

Para estimar o transbordamento do multiplicador da produção é necessário calcular o multiplicador de produção, o qual permite analisar o impacto de uma variação na demanda final de determinado setor sobre a variável econômica de interesse. (Miller e Blair, 1985).

Observando o Quadro 1 e dado que $X=(I-A)^{-1}$ é a matriz inversa de Leontief e lij seus elementos da linha $i$ e coluna $j$, o multiplicador setorial de produção do setor $j$ será:

$$
M P_{j}=\sum_{i=1}^{n} l_{i j}, \quad j=1, \ldots, n
$$

em que $M P j$ é o multiplicador de produção do tipo I.

O valor calculado representa o valor total de produção de toda a economia que é acionado para atender à variação de uma unidade na demanda final do setor $j$. No caso do presente estudo, existem duas regiões e quarenta e dois setores, portanto, $i=j=84$. O somatório dos elementos da matriz inversa referente à própria região constitui o efeito multiplicador interno, enquanto o somatório dos elementos da coluna $j$ referentes ao fluxo inter-regional de bens e serviços é o valor do transbordamento (efeito multiplicador fora da região de origem do setor). Como pode ser observado na equação (25) e Quadro 1, os elementos lij da matriz LL, somados em colunas, são o efeito multiplicador dentro da região L, enquanto os somatórios das colunas da matriz ML são efeitos do aumento de produção dos setores da região L para a região $\mathrm{M}$.

O valor calculado representa o valor total de produção de toda a economia que é acionado para atender à variação de uma unidade na demanda final do setor $j$. O efeito transbordamento de uma região em relação à outra é estimado pela diferença entre os multiplicadores dessas, podendo ser apresentado tanto em termos absolutos quanto em valores porcentuais. O efeito transbordamento mostra como o aumento da produção setorial em dada região impacta a produção dos setores de outra região.

\section{RESUltados E DisCUSSÃO}

\subsection{Relações sinérgicas entre regiões}

Os resultados das interações sinérgicas para as grandes regiões no ano de 1999 estão resumidos no Quadro 3, enquanto o Quadro 4 apresenta os resultados obtidos por Guilhoto (1999) para o ano de 1995. Analisando os resultados, nota-se que a produção da Região Norte é a mais dependente do fluxo de comércio entre esta e o restante do País (28,95\% em 1999), seguida das Regiões Nordeste $(24,5 \%)$, Centro-Oeste $(23,88 \%)$ e Sul (16,14\%). A Região Sudeste é menos dependente das vendas para o Restante do Brasil (RBR), as quais representam 10,94\% em 1999. Por outro lado, 12,84\% da produção do Restante do Brasil dependem do fluxo de insumos (bens e serviços) entre este e a Região Sudeste, o maior valor entre as regiões do País.

A comparação dos resultados obtidos para o ano de 1999 e aqueles obtidos por Guilhoto (1999) para 1995 indica que a Região Nordeste apresentou as maiores variações, aumentando a interação com as outras regiões do País. Pode-se afirmar que houve relativo aumento do fluxo de insumos no sentido Restante do Brasil-Nordeste, que resultou em maior dependência da estrutura produtiva (consumo intermediário) desta região em relação ao Restante do País, ao mesmo tempo que houve 
aumento das vendas de insumos das empresas nordestinas para o Restante do Brasil. Em 1999, as relações intersetoriais na Região Nordeste eram responsáveis por 65,67\% da produção, enquanto em 1995 este valor era de 73,12\%.

A classificação das regiões de acordo com os valores das interações sinérgicas com o Restante do Brasil é: Norte, Nordeste, Centro-oeste, Sul e Sudeste (Quadro 3). A maior interação sinérgica indica, ao mesmo tempo, a abertura da economia regional e sua relativa dependência em relação aos fluxos de bens e serviços utilizados no consumo intermediário. Portanto, pode-se prever que a Região Norte apresentará maior transbordamento do efeito multiplicador da produção setorial do que as Regiões Sul e Sudeste. Assim, o aumento global da produção regional implicará a necessidade de aumento do fluxo de comércio entre esta e o Restante do País e o conseqüente aumento da produção em outras localidades, gerando o efeito de transbordamento do multiplicador de produção.

Quadro 3 - Contribuição $(\%)$ de cada bloco de matriz para a participação total de $\left(y_{1}-f\right)$ em $y$ para as grandes Regiões do Brasil e Restante do Brasil, 1999

\begin{tabular}{|c|c|c|c|c|c|c|c|c|c|c|}
\hline & \multicolumn{2}{|c|}{ Região Sul } & \multicolumn{3}{|c|}{ Restante do Brasil } & \multicolumn{3}{|c|}{ Região Sudeste } & \multicolumn{2}{|c|}{ Restante do Brasil } \\
\hline \multirow[b]{2}{*}{ S } & S & RBR & \multirow[b]{2}{*}{ S } & S & RBR & \multirow[b]{2}{*}{ SE } & SE & RBR & SE & RBR \\
\hline & 79,94 & 16,14 & & 1,15 & 0,21 & & 85,85 & 10,94 & 3,34 & 0,37 \\
\hline RBR & 0,15 & 3,77 & RBR & 3,59 & 95,05 & RBR & 0,40 & 2,81 & 12,84 & 83,45 \\
\hline & \multicolumn{2}{|c|}{ Centro-Oeste } & \multicolumn{3}{|c|}{ Restante do Brasil } & & \multicolumn{2}{|c|}{ Norte } & \multicolumn{2}{|c|}{ Restante do Brasil } \\
\hline \multirow[b]{2}{*}{$\mathrm{CO}$} & $\mathrm{CO}$ & RBR & \multirow[b]{2}{*}{$\mathrm{CO}$} & $\mathrm{CO}$ & RBR & \multirow[b]{2}{*}{$\mathrm{N}$} & $\mathrm{N}$ & RBR & $\mathrm{N}$ & RBR \\
\hline & 70,17 & 23,88 & & 0,50 & 0,15 & & 61,89 & 28,95 & 0,37 & 0,18 \\
\hline RBR & 0,09 & 5,85 & RBR & 1,94 & 97,41 & RBR & 0,13 & 9,04 & 1,46 & 97,99 \\
\hline \multirow[b]{3}{*}{$\mathrm{NE}$} & \multicolumn{2}{|c|}{ Nordeste } & \multicolumn{3}{|c|}{ Restante do Brasil } & & & & & \\
\hline & $\mathrm{NE}$ & RBR & \multirow{3}{*}{$\begin{array}{r}\text { NE } \\
\text { RBR }\end{array}$} & $\mathrm{NE}$ & RBR & & & & & \\
\hline & 65,67 & 24,50 & & 0,71 & 0,26 & & & & & \\
\hline RBR & 0,38 & 9,45 & & 3,26 & 95,78 & & & & & \\
\hline
\end{tabular}

Fonte: Cálculos dos autores. 
Quadro 4 - Contribuição (\%) de cada bloco de matriz para a participação total de $\left(y_{l}-f\right)$ em y para as grandes Regiões do Brasil e Restante do Brasil, 1995

\begin{tabular}{|c|c|c|c|c|c|c|c|c|c|c|c|}
\hline & \multicolumn{2}{|c|}{ Região Sul } & & \multicolumn{2}{|c|}{ Restante do Brasil } & \multicolumn{3}{|c|}{ Região Sudeste } & & \multicolumn{2}{|c|}{ Restante do Brasil } \\
\hline \multirow[b]{2}{*}{$S$} & S & RBR & \multirow[b]{2}{*}{$\mathrm{s}$} & S & RBR & \multirow[b]{2}{*}{ SE } & SE & RBR & \multirow[b]{2}{*}{ SE } & SE & RBR \\
\hline & 76,86 & 18,54 & & 1,44 & 0,36 & & 84,52 & 12,15 & & 4,07 & 0,69 \\
\hline RBR & 0,29 & 4,31 & RBR & 5,82 & 92,38 & RBR & 0,60 & 2,72 & RBR & 15,38 & 79,85 \\
\hline \multirow[b]{3}{*}{$\mathrm{co}-a+a$} & \multicolumn{2}{|c|}{ Centro-Oeste } & \multicolumn{3}{|c|}{ Restante do Brasil } & \multirow[b]{3}{*}{$\mathrm{N}$} & \multicolumn{2}{|c|}{ Norte } & \multicolumn{3}{|c|}{ Restante do Brasil } \\
\hline & $\mathrm{CO}$ & RBR & \multirow[b]{2}{*}{$\mathrm{CO}$} & $\mathrm{CO}$ & RBR & & \multicolumn{2}{|r|}{ RBR } & & $\mathrm{N}$ & RBR \\
\hline & 68,44 & 25,11 & & 0,36 & 0,16 & & 64,33 & 27,32 & $\mathrm{~N}$ & 0,17 & 0,08 \\
\hline RBR & 0,11 & 6,34 & RBR & 1,74 & 97,73 & RBR & 0,23 & 8,12 & RBR & 1,40 & 98,35 \\
\hline \multirow[b]{3}{*}{ NE } & \multicolumn{2}{|c|}{ Nordeste } & \multicolumn{3}{|c|}{ Restante do Brasil } & & & & & & \\
\hline & NE & RBR & & NE & RBR & & & & & & \\
\hline & 73,12 & 18,99 & & 0,44 & 0,17 & & & & & & \\
\hline RBR & 0,35 & 7,53 & RBR & 2,30 & 97,09 & & & & & & \\
\hline
\end{tabular}

Fonte: Guilhoto et al. (2001).

\subsection{Transbordamento do efeito multiplicador de produção}

\subsubsection{Análise geral dos valores de transbordamento}

Os resultados estão resumidos nas Tabelas 2, 3 e 4 e Figuras 2, 3, 4 e 5. A análise dos resultados mostra que caso os setores das regiões Norte e Centro-Oeste aumentassem sua produção, cerca de $20 \%$ do efeito multiplicador teria impacto fora destas regiões. Nos casos das regiões Sul e Nordeste, este efeito de transbordamento seria de aproximadamente 13\%, e para a região Sudeste, de $8 \%$. Por outro lado, o transbordamento no sentido Restante do Brasil para a região em análise ocorreria em maior intensidade entre Sudeste e Restante do Brasil (10,4\%), sendo que para as outras regiões este valor não ultrapassaria 3,9\% (Nordeste). Pode-se afirmar que a Região Sudeste apresenta menor dependência em relação ao Restante do País e, simultaneamente, que o efeito transbordamento é favorável (relativamente maior no sentido Restante do Brasil para Sudeste).

\subsubsection{Análise do transbordamento do efeito multiplicador de produção dos setores das Grandes Regiões}

A análise detalhada dos resultados para cada região permite determinar caraterísticas específicas das estruturas produtivas e dos setores. O transbordamento do multiplicador de produção de um dado setor é causado pela necessidade de obter insumos provenientes de fora de sua região de origem. Portanto, quanto maior a necessidade de importação de insumos para abastecer o setor, maior será o transbordamento do efeito multplicador de produção. Estudos específicos para 
os setores podem ser realizados para conhecer as causas da importação de bens e serviços para as diferentes regiões.

\section{Região Sul}

A interação entre a Região Sul e o restante do País determina que cerca de $16 \%$ da produção desta depende do fluxo de bens e serviços em direção ao Restante do Brasil e 3,8\% do nível da produção deste último (resultados do ano de 1999). Ocorreram pequenas variações dos valores das interações sinérgicas entre a Região Sul e Restante do Brasil entre os anos de 1995 e 1999 (Quadros 3 e 4). O transbordamento do multiplicador de produção Sul-Restante do Brasil indica que os setores Siderurgia (5), Metalurgia (6) e Outros Produtos Metalúrgicos (7) apresentam os maiores valores. Portanto, o aumento da produção destas atividades na Região Sul do País geraria um efeito multiplicador que corresponderia entre $35 \%$ a $40 \%$ fora da região de origem. Por outro lado, no caso de ocorrer aumento de produção da indústria de alimentos no Restante do Brasil, haveria um transbordamento do efeito multiplicador da produção dentro da Região Sul que poderia variar entre 6\% e, no máximo, 11,3\%, no caso do setor Fabricação de óleos vegetais (Tabela 2 e Figuras 2 e 3).

\section{Região Sudeste}

Os resultados para as interações sinérgicas para os anos de 1995 e 1999 confirmam a maior dependência da produção do Restante do Brasil em relação à Região Sudeste. De fato, esta região é uma importante compradora de bens e serviços para consumo intermediário. Porém, esta dependência diminuiu no período 1995/99, pois no ano de 1995 a produção do Restante do Brasil dependia 15,38\% do fluxo de comércio em direção ao Sudeste, enquanto no ano de 1999 este valor caiu para $12,84 \%$. A dependência da produção da Região Sudeste em relação ao fluxo de comércio em direção ao Restante do País diminuiu de 12,15\% para 10,94\% (Quadros 3 e 4). O efeito transbordamento do multiplicador da produção indica que os setores Calçados (23), Indústria do Café (24), Beneficiamento de Produtos Vegetais (25), Abate de Animais (26) e Fabricação de Óleos Vegetais (29) apresentam maior impacto no sentido Sudeste-Restante do Brasil. A média do efeito transbordamento no sentido Restante do Brasil-Sudeste é ainda maior em termos porcentuais (10,4\%), sendo que os setores Siderurgia (5), Outros Produtos Metalúrgicos (7), Automóveis, caminhões e ônibus (11), Peças e outros veículos (12) e Indústria da Borracha (15) apresentam os maiores valores (Tabela 4 e Figura 4). Portanto, a Região Sudeste é dependente em relação ao consumo intermediário para a produção da agroindústria e fornecedora de bens manufaturados de maior valor agregado e tecnologia para outras indústrias localizadas no restante do Brasil.

\section{Região Centro-Oeste}

A Região Centro-Oeste apresenta dependência relativamente alta (interações sinérgicas importantes) comparativamente às outras regiões no referente às suas vendas para consumo intermediário do Restante do Brasil, pois aproximadamente $24 \%$ da produção regional são destinados ao consumo intermediário em outras regiões. Além disto, o próprio nível da produção no Restante do País é responsável pela demanda de cerca de $6 \%$ da produção do Centro-Oeste. Por outro lado, o Restante do Brasil não depende, de forma expressiva, desta região: 2,59\% da produção do Restante do Brasil (Quadro 3). Estes resultados foram obtidos para o ano de 1999, porém não ocorreram modificações importantes no período 1995/99. Os resultados do efeito transbordamento indicam valores entre $18 \%$ e $38 \%$ para a maior parte dos setores do Centro-Oeste, uma alta dependência dos insumos 
destinados ao consumo intermediário destas atividades. O transbordamento no sentido Restante do Brasil-Centro-Oeste ocorre principalmente para os setores ligados à agroindústria, o que indica que o aumento da produção agroindustrial do Restante do Brasil geraria estímulo importante para o aumento da produção agropecuária no Centro-Oeste (Tabela 4 e Figura 4).

\section{Região Norte}

Os resultados dos cálculos das interações sinérgicas entre o Norte e Restante do Brasil mostram que esta região é a mais dependente (apresenta maior sinergia) das relações comerciais com as outras regiões do País, pois aproximadamente 38\% da produção total depende dos fluxos de comércio e nível da produção no Restante do País. A proporção da produção do Restante do Brasil que depende destas relações é de aproximadamente 2\% (Quadro 3). Esta situação de dependência não apresenta modificações expressivas no período 1995/99. A conseqüência desta dependência é um grande efeito transbordamento no sentido Norte-Restante do Brasil em vários setores, principalmente Siderurgia (5), Metalurgia (6), Outros produtos metalúrgicos (7), Artigos Plásticos (20) e Indústria Têxtil (21), caso similar ao da Região Centro-Oeste. O efeito transbordamento no sentido Restante do Brasil-Norte é maior nos setores Extrativismo Mineral (2), Metalurgia de não-ferrosos (6) e Madeira e mobiliário (13), uma vez que a Região Norte é tradicional fornecedora de matériaprima para estas indústrias localizadas em outras regiões. Porém, é importante notar que o valor do efeito multiplicador do transbordamento é relativamente pequeno (Tabela 4 e Figura 4).

\section{Região Nordeste}

O efeito de sinergia entre a Região Nordeste e o Restante do Brasil é relativamente grande: cerca de $34 \%$ da produção regional é destinada a suprir o consumo intermediário do Restante do País, enquanto $4 \%$ da produção do Restante do Brasil dependem das relações com esta região. Portanto, o efeito transbordamento do multiplicador da produção será muito maior no sentido Nordeste-Restante do Brasil, como se pode comprovar analisando os resultados das Tabelas 3 e Figura 5. No Nordeste, os setores que apresentam maior efeito transbordamento são Material elétrico (9), Automóveis, caminhões e ônibus (11), Peças e outros veículos (12), Celulose, papel e gráfica (14) e Fabricação de Óleos Vegetais (29). Para que estas atividades aumentem sua produção no Nordeste, no mínimo $20 \%$ do efeito multiplicador da produção ocorrerá no restante do Brasil. O efeito transbordamento no sentido Restante do Brasil-Nordeste é maior para os setores de Metalurgia de nãoferrosos (6), Material Elétrico (9), Refino de Petróleo (17), Artigos Plásticos (20) e Transportes (35), pois parte importante do consumo destes setores é de matérias-primas provenientes do Nordeste do País (Tabela 4 e Figura 5). 
Tabela 2 - Transbordamento do multiplicador de produção tipo I entre a Região Sul (S) e o Restante do Brasil (RBR), 1999

\begin{tabular}{|c|c|c|c|c|c|c|c|}
\hline \multirow{4}{*}{ Setores } & & \multicolumn{6}{|c|}{ Sistema Região Sul e Restante do Brasil (RBR) } \\
\hline & & \multicolumn{3}{|c|}{ Região Sul } & \multicolumn{3}{|c|}{ Restante do Brasil } \\
\hline & & \multirow{2}{*}{$\begin{array}{l}\text { Região } \\
\text { Sul } \\
\text { valor }\end{array}$} & \multicolumn{2}{|c|}{$\begin{array}{l}\text { Transbordamento para o } \\
\text { Restante do Brasil }\end{array}$} & \multirow{2}{*}{$\begin{array}{l}\text { Restante do } \\
\text { Brasil } \\
\text { valor }\end{array}$} & \multicolumn{2}{|c|}{$\begin{array}{l}\text { Transbordamento } \\
\text { para a Região Su }\end{array}$} \\
\hline & & & valor & $(\%)$ & & valor & $(\%)$ \\
\hline 1 & Agropecuária & 1,6 & 0,1 & 8,4 & 1,7 & 0,1 & 3,4 \\
\hline 2 & Extrativa Mineral & 1,5 & 0,3 & 16,7 & 1,8 & 0,0 & 1,1 \\
\hline 3 & Petróleo e gás & 1,3 & 0,1 & 9,0 & 1,4 & 0,0 & 0,8 \\
\hline 4 & Minerais não-metálicos & 1,7 & 0,3 & 13,0 & 1,9 & 0,0 & 0,9 \\
\hline 5 & Siderurgia & 1,5 & 1,0 & 39,4 & 2,5 & 0,0 & 1,5 \\
\hline 6 & Metalurgia de não-ferrosos & 1,5 & 0,8 & 34,9 & 2,2 & 0,0 & 1,3 \\
\hline 7 & Outros Produtos Metalúrgicos & 1,5 & 0,8 & 34,1 & 2,3 & 0,0 & 1,2 \\
\hline 8 & Máquinas e Equipamentos & 1,4 & 0,3 & 17,3 & 1,7 & 0,0 & 1,1 \\
\hline 9 & Material Elétrico & 1,6 & 0,6 & 25,4 & 2,2 & 0,0 & 1,4 \\
\hline 10 & Equipamentos Eletrônicos & 1,5 & 0,2 & 14,3 & 1,7 & 0,0 & 1,5 \\
\hline 11 & Automóveis, caminhões e ônibus & 1,6 & 0,4 & 21,8 & 2,0 & 0,0 & 1,2 \\
\hline 12 & Peças e outros veículos & 1,6 & 0,5 & 23,1 & 2,1 & 0,0 & 1,5 \\
\hline 13 & Madeira e Mobiliário & 1,8 & 0,2 & 8,1 & 1,8 & 0,1 & 6,6 \\
\hline 14 & Celulose, Papel e Gráfica & 1,9 & 0,2 & 8,7 & 2,1 & 0,0 & 2,3 \\
\hline 15 & Indústria da Borracha & 1,8 & 0,3 & 14,0 & 2,1 & 0,0 & 1,5 \\
\hline 16 & Elementos Químicos & 1,7 & 0,2 & 11,8 & 1,8 & 0,1 & 3,6 \\
\hline 17 & Refino de Petróleo & 1,5 & 0,4 & 22,6 & 1,9 & 0,0 & 0,6 \\
\hline 18 & Químicos Diversos & 1,7 & 0,3 & 16,2 & 2,0 & 0,0 & 1,7 \\
\hline 19 & Farmacêuticos e Veterinários & 1,6 & 0,3 & 13,4 & 1,8 & 0,1 & 3,9 \\
\hline 20 & Artigos Plásticos & 1,8 & 0,2 & 12,4 & 2,0 & 0,0 & 0,9 \\
\hline 21 & Indústria Têxtil & 2,2 & 0,2 & 7,5 & 2,3 & 0,1 & 2,9 \\
\hline 22 & Artigos do Vestuário & 2,0 & 0,1 & 5,5 & 2,1 & 0,1 & 2,7 \\
\hline 23 & Calçados & 1,9 & 0,2 & 8,2 & 1,8 & 0,2 & 9,0 \\
\hline 24 & Indústria do Café & 2,2 & 0,1 & 5,1 & 2,2 & 0,2 & 7,0 \\
\hline 25 & Beneficiamento de Produtos Vegetais & 2,0 & 0,1 & 6,7 & 2,0 & 0,1 & 6,5 \\
\hline 26 & Abate de Animais & 2,3 & 0,2 & 6,5 & 2,2 & 0,2 & 8,8 \\
\hline 27 & Indústria de Laticínios & 2,1 & 0,1 & 6,1 & 2,1 & 0,1 & 6,0 \\
\hline 28 & Fabricação de Açúcar & 1,9 & 0,4 & 17,1 & 2,2 & 0,1 & 4,3 \\
\hline 29 & Fabricação de Óleos Vegetais & 2,2 & 0,2 & 6,6 & 2,1 & 0,3 & 11,3 \\
\hline 30 & Outros Produtos Alimentares & 2,0 & 0,2 & 9,4 & 2,1 & 0,2 & 8,3 \\
\hline 31 & Indústrias Diversas & 1,6 & 0,3 & 16,0 & 1,9 & 0,0 & 1,8 \\
\hline 32 & Serv. Indust.e de Utilidade Pública & 1,6 & 0,1 & 4,8 & 1,6 & 0,0 & 1,2 \\
\hline 33 & Construção Civil & 1,5 & 0,2 & 11,5 & 1,7 & 0,0 & 1,6 \\
\hline 34 & Comércio & 1,6 & 0,2 & 12,7 & 1,8 & 0,0 & 0,7 \\
\hline 35 & Transportes & 1,7 & 0,3 & 14,2 & 1,9 & 0,0 & 0,6 \\
\hline 36 & Comunicações & 1,2 & 0,1 & 6,4 & 1,3 & 0,0 & 0,6 \\
\hline 37 & Instituições Financeiras & 1,3 & 0,1 & 10,2 & 1,4 & 0,0 & 0,7 \\
\hline 38 & Serviços Prestados às Famílias & 1,5 & 0,2 & 10,6 & 1,7 & 0,1 & 3,1 \\
\hline 39 & Serviços Prestados às Empresas & 1,4 & 0,1 & 6,2 & 1,4 & 0,0 & 1,3 \\
\hline 40 & Aluguel de Imóveis & 1,1 & 0,0 & 1,4 & 1,1 & 0,0 & 0,1 \\
\hline 41 & Administração Pública & 1,3 & 0,1 & 7,4 & 1,4 & 0,0 & 1,2 \\
\hline \multirow{2}{*}{42} & Serviços Privados não-mercantis & 1,1 & 0,0 & 1,7 & 1,1 & 0,0 & 1,0 \\
\hline & Média & 1,7 & 0,3 & 13,0 & 1,9 & 0,1 & 2,8 \\
\hline
\end{tabular}

Fonte: Cálculos dos autores. 
Figura 2 - Transbordamento do multiplicador de produção tipo I (\%) dos setores da Região Sul para o Restante do Brasil (RBR), 1999

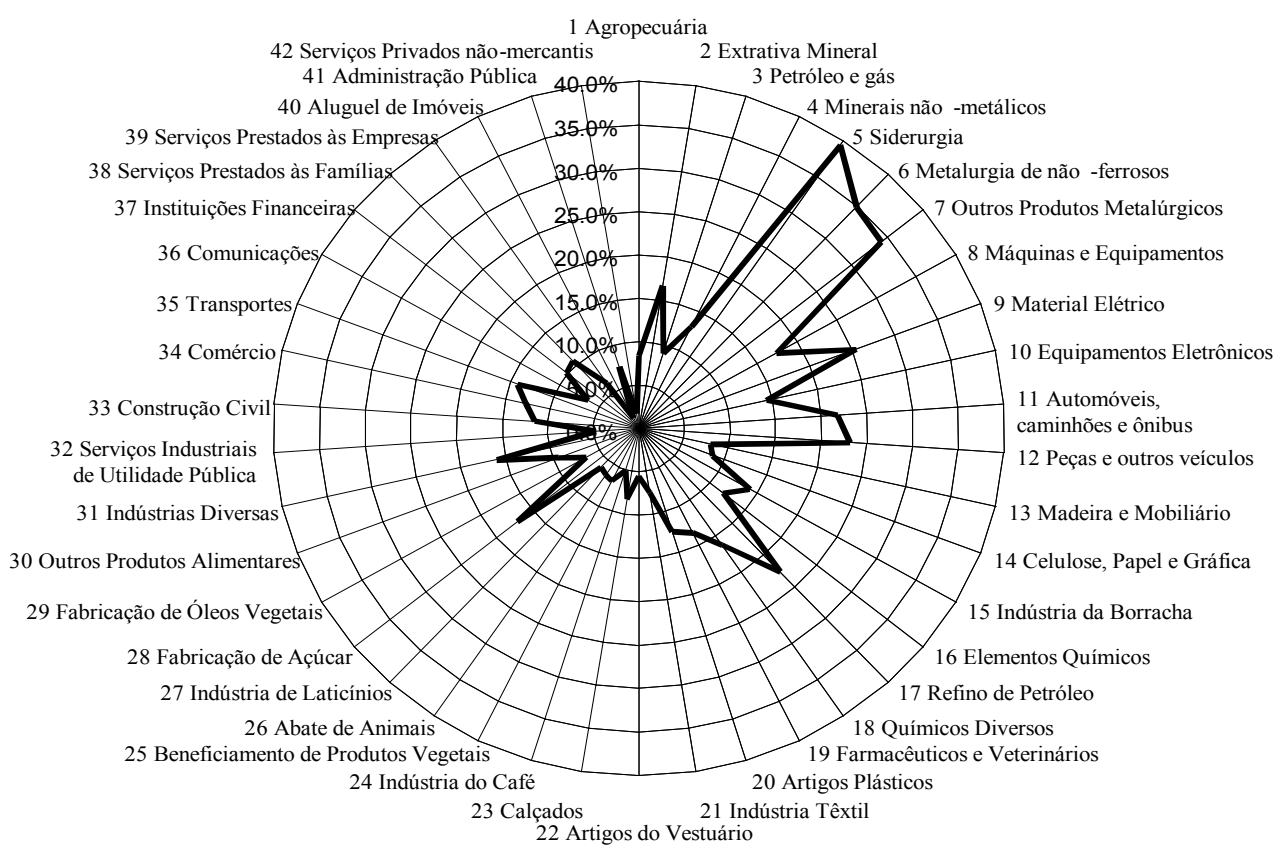

Fonte: Tabela 2.

Figura 3 - Transbordamento do multiplicador de produção tipo I (\%) dos setores do Restante do Brasil para a Região Sul, 1999

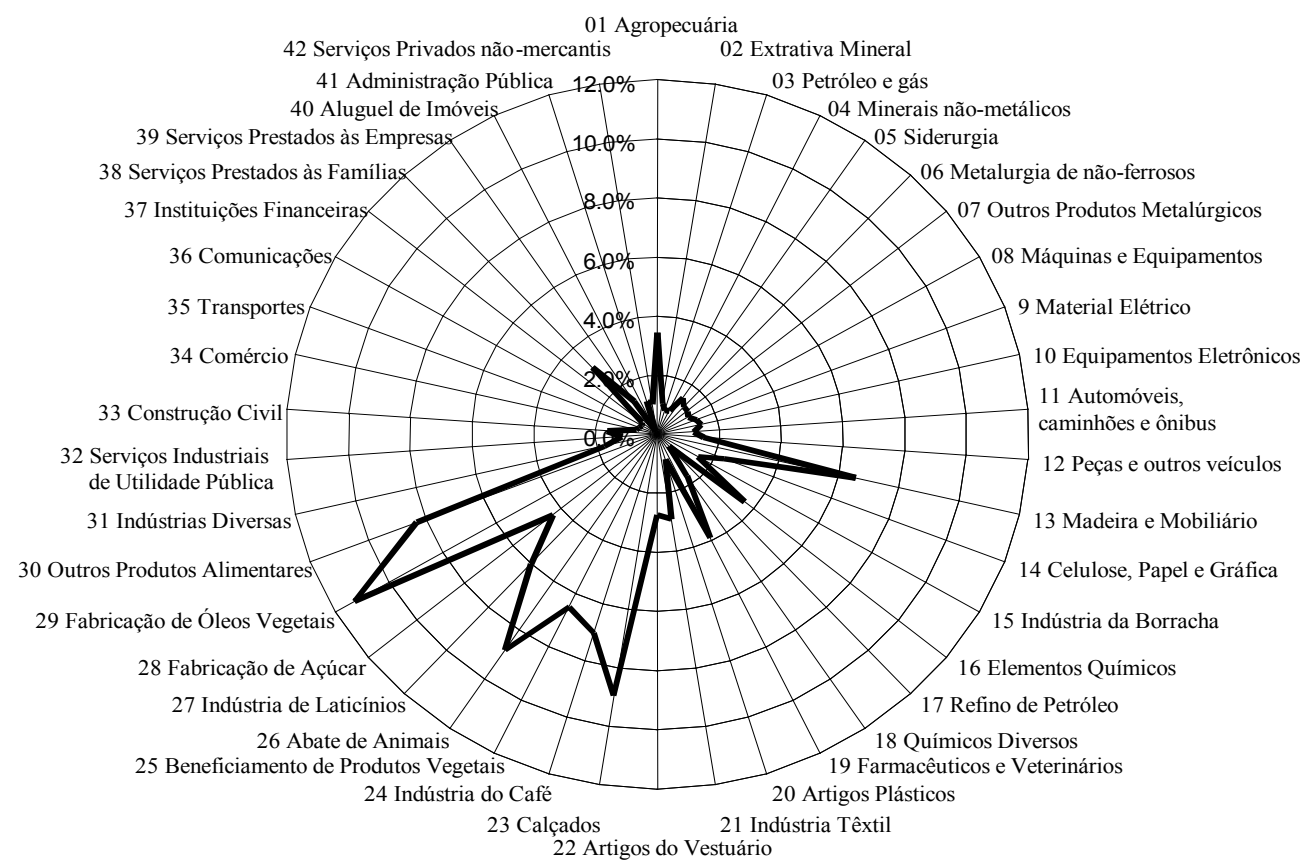

Fonte: Tabela 2. 
Tabela 3 - Transbordamento do multiplicador de produção tipo I (valores) entre as Regiões
Sudeste, Centro-Oeste, Norte e Nordeste e o Restante do Brasil (RBR), 1999

\begin{tabular}{|c|c|c|c|c|c|c|c|c|}
\hline \multirow{2}{*}{ Setores } & \multicolumn{2}{|c|}{$\begin{array}{c}\text { Sistema Região Sudeste } \\
\text { e Restante do Brasil } \\
\text { (RBR) }\end{array}$} & \multicolumn{2}{|c|}{$\begin{array}{c}\text { Sistema Região Centro-Oeste } \\
\text { e Restante do Brasil }\end{array}$} & \multicolumn{2}{|c|}{$\begin{array}{l}\text { Sistema Região Norte e } \\
\text { Restante do Brasil }\end{array}$} & \multicolumn{2}{|c|}{$\begin{array}{c}\text { Sistema Região Nordeste e } \\
\text { Restante do Brasil }\end{array}$} \\
\hline & $\begin{array}{l}\text { Sudeste } \\
\text { para RBR }\end{array}$ & $\begin{array}{l}\text { RBR para } \\
\text { Sudeste }\end{array}$ & $\begin{array}{l}\text { Centro-Oeste } \\
\text { para RBR }\end{array}$ & $\begin{array}{c}\text { RBR para } \\
\text { Centro-Oeste }\end{array}$ & $\begin{array}{c}\text { Norte } \\
\text { para RBR }\end{array}$ & $\begin{array}{l}\text { RBR para } \\
\text { Norte }\end{array}$ & $\begin{array}{l}\text { Nordeste } \\
\text { para RBR }\end{array}$ & $\begin{array}{l}\text { RBR para } \\
\text { Nordeste }\end{array}$ \\
\hline 1 Agropecuária & 0,2 & 0,1 & 0,3 & 0,0 & 0,2 & 0,0 & 0,1 & 0,1 \\
\hline 2 Extrativa Mineral & 0,1 & 0,2 & 0,4 & 0,0 & 0,4 & 0,1 & 0,3 & 0,1 \\
\hline 3 Petróleo e gás & 0,0 & 0,1 & 0,2 & 0,0 & 0,2 & 0,0 & 0,2 & 0,0 \\
\hline 4 Minerais não-metálicos & 0,1 & 0,2 & 0,4 & 0,0 & 0,4 & 0,0 & 0,3 & 0,1 \\
\hline 5 Siderurgia & 0,1 & 0,7 & 1,0 & 0,0 & 0,8 & 0,0 & 0,3 & 0,1 \\
\hline 6 Metalurgia de não-ferrosos & 0,1 & 0,2 & 0,7 & 0,0 & 0,4 & 0,1 & 0,3 & 0,3 \\
\hline 7 Outros Produtos Metalúrgicos & 0,1 & 0,6 & 0,9 & 0,0 & 0,7 & 0,0 & 0,3 & 0,1 \\
\hline 8 Máquinas e Equipamentos & 0,0 & 0,3 & 0,4 & 0,0 & 0,3 & 0,0 & 0,3 & 0,0 \\
\hline 9 Material Elétrico & 0,1 & 0,4 & 0,7 & 0,0 & 0,6 & 0,0 & 0,5 & 0,1 \\
\hline 10 Equipamentos Eletrônicos & 0,0 & 0,2 & 0,4 & 0,0 & 0,3 & 0,0 & 0,3 & 0,0 \\
\hline 11 Automóveis, caminhões e ônibus & 0,1 & 0,4 & 0,7 & 0,0 & 0,4 & 0,0 & 0,6 & 0,1 \\
\hline 12 Peças e outros veículos & 0,1 & 0,4 & 0,7 & 0,0 & 0,5 & 0,0 & 0,6 & 0,1 \\
\hline 13 Madeira e Mobiliário & 0,3 & 0,1 & 0,4 & 0,0 & 0,3 & 0,0 & 0,3 & 0,1 \\
\hline 14 Celulose, Papel e Gráfica & 0,1 & 0,3 & 0,6 & 0,0 & 0,5 & 0,0 & 0,5 & 0,1 \\
\hline 15 Indústria da Borracha & 0,2 & 0,3 & 0,6 & 0,0 & 0,5 & 0,0 & 0,3 & 0,1 \\
\hline 16 Elementos Químicos & 0,2 & 0,1 & 0,3 & 0,0 & 0,3 & 0,0 & 0,2 & 0,1 \\
\hline 17 Refino de Petróleo & 0,1 & 0,2 & 0,6 & 0,0 & 0,5 & 0,0 & 0,1 & 0,2 \\
\hline 18 Químicos Diversos & 0,1 & 0,2 & 0,7 & 0,0 & 0,5 & 0,0 & 0,2 & 0,1 \\
\hline 19 Farmacêuticos e Veterinários & 0,1 & 0,2 & 0,4 & 0,0 & 0,3 & 0,0 & 0,4 & 0,1 \\
\hline 20 Artigos Plásticos & 0,2 & 0,2 & 0,7 & 0,0 & 0,7 & 0,0 & 0,2 & 0,2 \\
\hline 21 Indústria Têxtil & 0,2 & 0,2 & 0,9 & 0,0 & 0,7 & 0,0 & 0,2 & 0,1 \\
\hline 22 Artigos do Vestuário & 0,1 & 0,2 & 0,8 & 0,0 & 0,6 & 0,0 & 0,2 & 0,1 \\
\hline 23 Calçados & 0,3 & 0,2 & 0,4 & 0,0 & 0,4 & 0,0 & 0,3 & 0,1 \\
\hline 24 Indústria do Café & 0,5 & 0,1 & 0,4 & 0,1 & 0,2 & 0,1 & 0,1 & 0,1 \\
\hline 25 Beneficiamento de Prod. Vegetais & 0,4 & 0,1 & 0,3 & 0,1 & 0,3 & 0,0 & 0,2 & 0,1 \\
\hline 26 Abate de Animais & 0,6 & 0,1 & 0,3 & 0,1 & 0,3 & 0,1 & 0,2 & 0,1 \\
\hline 27 Indústria de Laticínios & 0,4 & 0,1 & 0,3 & 0,1 & 0,3 & 0,1 & 0,2 & 0,1 \\
\hline 28 Fabricação de Açúcar & 0,3 & 0,3 & 0,5 & 0,0 & 0,4 & 0,0 & 0,3 & 0,1 \\
\hline 29 Fabricação de Óleos Vegetais & 0,6 & 0,2 & 0,4 & 0,1 & 0,4 & 0,0 & 0,5 & 0,1 \\
\hline 30 Outros Produtos Alimentares & 0,4 & 0,2 & 0,4 & 0,1 & 0,5 & 0,0 & 0,4 & 0,1 \\
\hline 31 Indústrias Diversas & 0,1 & 0,2 & 0,4 & 0,0 & 0,4 & 0,0 & 0,3 & 0,1 \\
\hline $\begin{array}{l}\text { Serviços Industriais de Utilidade } \\
\text { Pública }\end{array}$ & 0,1 & 0,1 & 0,2 & 0,0 & 0,2 & 0,0 & 0,1 & 0,0 \\
\hline 33 Construção Civil & 0,1 & 0,2 & 0,3 & 0,0 & 0,3 & 0,0 & 0,3 & 0,0 \\
\hline 34 Comércio & 0,1 & 0,1 & 0,4 & 0,0 & 0,5 & 0,0 & 0,2 & 0,1 \\
\hline 35 Transportes & 0,1 & 0,2 & 0,6 & 0,0 & 0,5 & 0,0 & 0,3 & 0,1 \\
\hline 36 Comunicações & 0,0 & 0,1 & 0,1 & 0,0 & 0,1 & 0,0 & 0,1 & 0,0 \\
\hline 37 Instituições Financeiras & 0,0 & 0,2 & 0,1 & 0,0 & 0,3 & 0,0 & 0,2 & 0,0 \\
\hline 38 Serviços Prestados às Famílias & 0,1 & 0,2 & 0,3 & 0,0 & 0,2 & 0,0 & 0,2 & 0,0 \\
\hline 39 Serviços Prestados às Empresas & 0,0 & 0,1 & 0,2 & 0,0 & 0,2 & 0,0 & 0,2 & 0,0 \\
\hline 40 Aluguel de Imóveis & 0,0 & 0,0 & 0,0 & 0,0 & 0,0 & 0,0 & 0,0 & 0,0 \\
\hline 41 Administração Pública & 0,0 & 0,1 & 0,1 & 0,0 & 0,2 & 0,0 & 0,1 & 0,0 \\
\hline 42 Serviços Privados não-mercantis & 0,0 & 0,0 & 0,0 & 0,0 & 0,0 & 0,0 & 0,0 & 0,0 \\
\hline Média & 0,2 & 0,2 & 0,4 & 0,0 & 0,4 & 0,0 & 0,3 & 0,1 \\
\hline
\end{tabular}

Fonte: Cálculos dos autores. 
Tabela 4 - Transbordamento do multiplicador de produção tipo I (\%) entre as Regiões Sudeste, Centro-Oeste, Norte e Nordeste e o Restante do Brasil (RBR), 1999

\begin{tabular}{|c|c|c|c|c|c|c|c|c|}
\hline \multirow{2}{*}{ Setores } & \multicolumn{2}{|c|}{$\begin{array}{c}\text { Sistema Região } \\
\text { Sudeste e Restante } \\
\text { do Brasil (RBR) }\end{array}$} & \multicolumn{2}{|c|}{$\begin{array}{c}\text { Sistema Região } \\
\text { Centro-Oeste e } \\
\text { Restante do Brasil }\end{array}$} & \multicolumn{2}{|c|}{$\begin{array}{l}\text { Sistema Região } \\
\text { Norte e Restante } \\
\text { do Brasil }\end{array}$} & \multicolumn{2}{|c|}{$\begin{array}{c}\text { Sistema Região } \\
\text { Nordeste e Restante } \\
\text { o Brasil }\end{array}$} \\
\hline & $\begin{array}{c}\text { Sudeste } \\
\text { para RBR }\end{array}$ & $\begin{array}{l}\text { RBR para } \\
\text { Sudeste }\end{array}$ & $\begin{array}{c}\text { Centro- } \\
\text { Oeste para } \\
\text { RBR }\end{array}$ & $\begin{array}{c}\text { RBR para } \\
\text { Centro- } \\
\text { Oeste }\end{array}$ & $\begin{array}{c}\text { Norte para } \\
\text { RBR }\end{array}$ & $\begin{array}{l}\text { RBR para } \\
\text { Norte }\end{array}$ & $\begin{array}{l}\text { Nordeste } \\
\text { para RBR }\end{array}$ & $\begin{array}{l}\text { RBR para } \\
\text { Nordeste }\end{array}$ \\
\hline 1 Agropecuária & 10,9 & 5,6 & 18,4 & 1,7 & 13,0 & 1,6 & 7,8 & 3,5 \\
\hline 2 Extrativa Mineral & 4,1 & 10,7 & 22,5 & 0,3 & 21,0 & 2,9 & 17,5 & 3,4 \\
\hline 3 Petróleo e gás & 1,9 & 9,4 & 14,8 & 0,1 & 14,9 & 0,4 & 13,1 & 1,6 \\
\hline 4 Minerais não-metálicos & 4,1 & 10,8 & 19,8 & 0,4 & 22,1 & 1,7 & 14,4 & 3,4 \\
\hline 5 Siderurgia & 4,4 & 27,6 & 38,7 & 0,5 & 33,9 & 1,7 & 11,7 & 2,7 \\
\hline 6 Metalurgia de não-ferrosos & 4,9 & 8,1 & 30,7 & 0,4 & 17,5 & 2,6 & 13,1 & 11,3 \\
\hline 7 Outros Produtos Metalúrgicos & 3,2 & 24,3 & 37,9 & 0,3 & 30,6 & 1,0 & 14,7 & 3,9 \\
\hline 8 Máquinas e Equipamentos & 2,3 & 15,4 & 25,4 & 0,2 & 19,7 & 0,7 & 16,8 & 2,7 \\
\hline 9 Material Elétrico & 3,6 & 17,4 & 33,9 & 0,2 & 25,8 & 1,0 & 21,2 & 6,6 \\
\hline 10 Equipamentos Eletrônicos & 2,8 & 12,7 & 21,6 & 0,2 & 17,4 & 1,9 & 20,5 & 2,7 \\
\hline 11 Automóveis, caminhões e ônibus & 2,6 & 21,5 & 32,7 & 0,2 & 20,7 & 1,7 & 27,8 & 2,6 \\
\hline 12 Peças e outros veículos & 2,9 & 20,3 & 35,1 & 0,2 & 22,8 & 1,4 & 26,3 & 3,8 \\
\hline 13 Madeira e Mobiliário & 13,1 & 7,5 & 18,3 & 1,4 & 16,0 & 2,0 & 17,0 & 3,5 \\
\hline 14 Celulose, Papel e Gráfica & 4,8 & 13,8 & 30,0 & 0,5 & 21,7 & 1,0 & 23,2 & 2,9 \\
\hline 15 Indústria da Borracha & 7,3 & 15,7 & 30,5 & 0,6 & 25,2 & 0,8 & 15,4 & 6,3 \\
\hline 16 Elementos Químicos & 11,6 & 7,7 & 16,8 & 1,8 & 14,0 & 1,9 & 10,3 & 3,9 \\
\hline 17 Refino de Petróleo & 6,0 & 10,8 & 32,6 & 0,2 & 26,3 & 0,7 & 7,9 & 8,4 \\
\hline 18 Químicos Diversos & 6,9 & 8,5 & 32,0 & 0,9 & 23,0 & 1,9 & 10,7 & 6,3 \\
\hline 19 Farmacêuticos e Veterinários & 8,0 & 11,2 & 20,7 & 2,1 & 18,1 & 1,0 & 19,6 & 3,2 \\
\hline 20 Artigos Plásticos & 8,1 & 8,1 & 37,0 & 0,2 & 34,4 & 0,7 & 10,2 & 9,9 \\
\hline 21 Indústria Têxtil & 7,2 & 8,0 & 36,1 & 0,8 & 29,7 & 0,9 & 8,4 & 6,0 \\
\hline 22 Artigos do Vestuário & 4,2 & 7,7 & 34,8 & 0,4 & 28,5 & 0,5 & 7,6 & 4,9 \\
\hline 23 Calçados & 15,5 & 9,4 & 20,7 & 1,2 & 17,7 & 1,4 & 12,9 & 5,3 \\
\hline 24 Indústria do Café & 21,3 & 4,5 & 18,0 & 3,5 & 9,8 & 2,3 & 5,9 & 4,9 \\
\hline 25 Beneficiamento de Produtos Vegetais & 19,7 & 6,4 & 14,7 & 3,1 & 14,7 & 2,1 & 9,6 & 3,6 \\
\hline 26 Abate de Animais & 26,6 & 5,7 & 13,4 & 4,2 & 12,3 & 2,9 & 8,3 & 4,4 \\
\hline 27 Indústria de Laticínios & 17,9 & 6,3 & 12,8 & 3,7 & 11,5 & 2,3 & 9,3 & 3,3 \\
\hline 28 Fabricação de Açúcar & 13,3 & 12,8 & 20,7 & 2,0 & 16,0 & 1,6 & 11,4 & 4,8 \\
\hline 29 Fabricação de Óleos Vegetais & 24,7 & 6,3 & 14,8 & 6,0 & 15,0 & 1,9 & 21,5 & 3,4 \\
\hline 30 Outros Produtos Alimentares & 16,3 & 8,5 & 18,7 & 2,9 & 20,9 & 1,4 & 15,7 & 3,3 \\
\hline 31 Indústrias Diversas & 4,4 & 11,5 & 22,9 & 0,3 & 22,3 & 1,6 & 16,9 & 4,2 \\
\hline 32 Serviços Industriais de Utilidade Pública & 4,7 & 5,1 & 14,0 & 0,1 & 9,5 & 1,2 & 7,5 & 2,1 \\
\hline 33 Construção Civil & 3,4 & 11,4 & 18,3 & 0,3 & 17,2 & 0,9 & 16,0 & 2,6 \\
\hline 34 Comércio & 5,6 & 8,3 & 23,7 & 0,4 & 26,4 & 0,7 & 10,4 & 6,1 \\
\hline 35 Transportes & 5,5 & 12,1 & 29,1 & 0,2 & 28,4 & 0,7 & 15,6 & 6,5 \\
\hline 36 Comunicações & 1,2 & 6,7 & 9,2 & 0,2 & 9,8 & 0,5 & 9,7 & 0,9 \\
\hline 37 Instituições Financeiras & 1,3 & 10,5 & 10,3 & 0,2 & 17,7 & 0,2 & 13,7 & 0,7 \\
\hline 38 Serviços Prestados às Famílias & 7,2 & 10,1 & 17,3 & 1,1 & 14,0 & 1,1 & 13,0 & 2,5 \\
\hline 39 Serviços Prestados às Empresas & 2,0 & 8,7 & 14,1 & 0,3 & 13,7 & 0,4 & 14,4 & 1,1 \\
\hline 40 Aluguel de Imóveis & 0,8 & 0,9 & 1,4 & 0,1 & 1,4 & 0,1 & 1,3 & 0,4 \\
\hline 41 Administração Pública & 2,9 & 7,4 & 9,7 & 0,4 & 13,3 & 0,5 & 10,0 & 1,2 \\
\hline \multirow{2}{*}{$\frac{42 \text { Serviços Privados não-mercantis }}{\text { Média }}$} & 2,3 & 1,7 & 3,2 & 0,3 & 3,5 & 0,3 & 2,8 & 0,7 \\
\hline & 7,6 & 10,4 & 22,1 & 1,1 & 18,8 & 1,3 & 13,4 & 3,9 \\
\hline
\end{tabular}

Fonte: Cálculos dos autores. 
Figura 4 - Transbordamento do multiplicador de produção tipo I entre as Regiões do Brasil (Sudeste, Centro-Oeste, Norte) e Restante do Brasil (RBR)

Transbordamento Sudeste para Restante do Brasil (escala $0-30 \%$ )

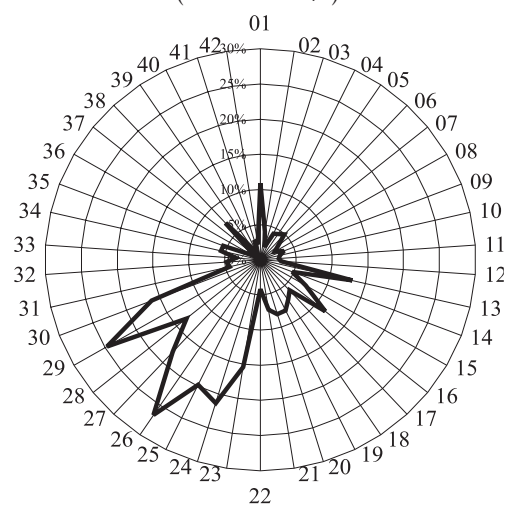

Transbordamento Centro-oeste para Restante do Brasil (escala $0-40 \%)$

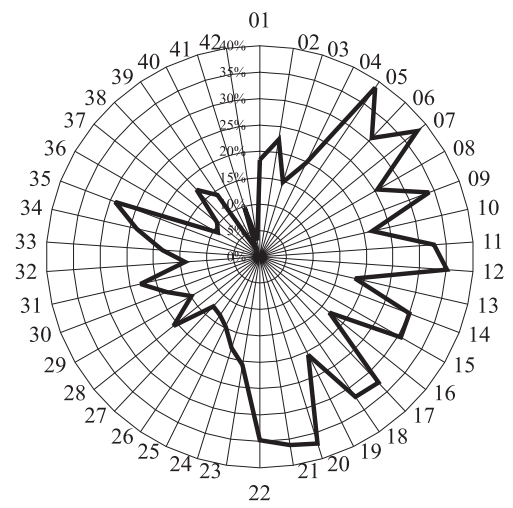

Transbordamento Norte para Restante do Brasil (escala $0-35 \%)$

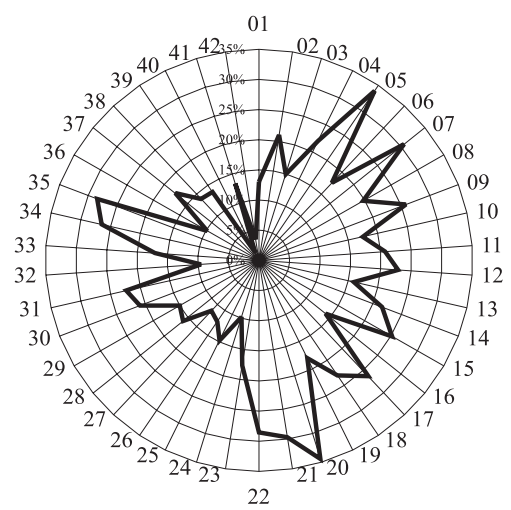

Transbordamento Restante do Brasil para Sudeste (escala $0-30 \%$ )

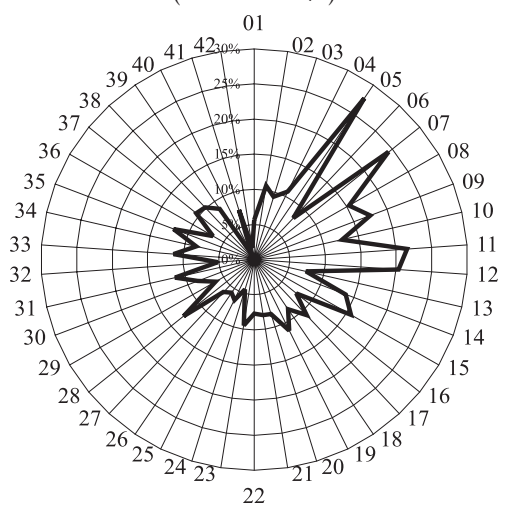

Transbordamento Restante do Brasil para Centro-oeste (escala $0-8 \%$ )

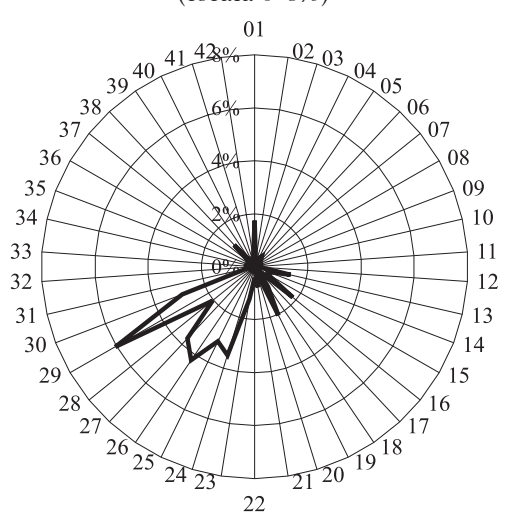

Transbordamento Restante do Brasil para Norte (escala $0-5 \%$ )

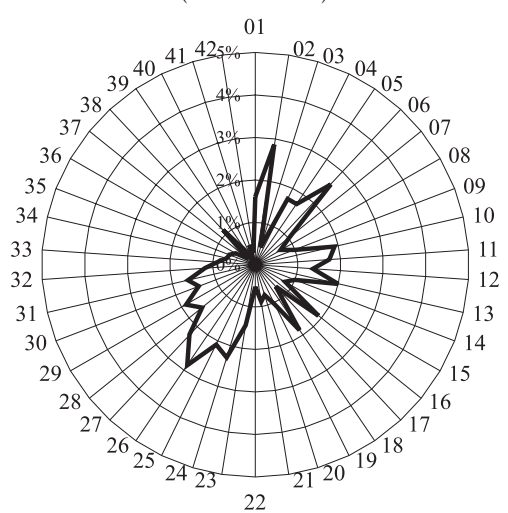




\section{Figura 5 - Transbordamento do multiplicador de produção tipo I entre as Região Nordeste e Restante do Brasil (RBR)}

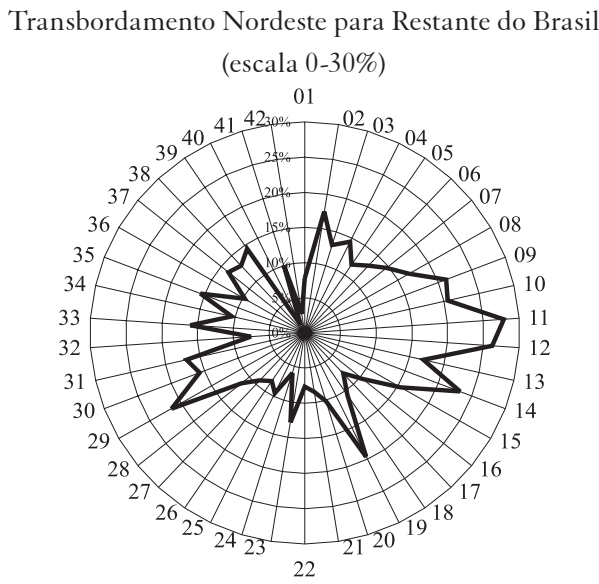

Transbordamento Restante do Brasil para Nordeste

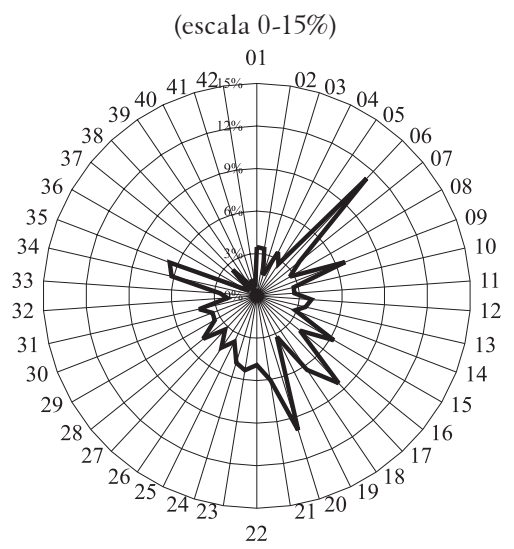

\section{CONSIDERAÇÕES FINAIS}

A maior interação entre as regiões do País pode levar a ganhos importantes no crescimento econômico, porém pode levar à dependência de determinadas regiões de insumos e mercado consumidor existentes nas outras regiões, provocando o efeito transbordamento do multiplicador de produção. Portanto, o aumento do fluxo de comércio inter-regional apresenta dois efeitos entre diferentes estruturas produtivas: sinergia e transbordamento do multiplicador de produção. A sinergia pode ser interpretada também como dependência do fluxo de bens e serviços para alimentar o processo produtivo dentro da região analisada. No período de 1995/99, a dependência das regiões Sul, Sudeste e Centro-Oeste em relação ao Restante do Brasil diminuiu, ao passo que para as regiões Norte e Nordeste elevou-se, notadamente para esta última. Isto indica maior interação comercial destas últimas regiões com o Restante do Brasil.

A elaboração de estratégias de desenvolvimento regional deve contemplar análises da estrutura produtiva (cadeia) dos setores a serem beneficiados por políticas públicas, pois os componentes da cadeia produtiva podem estar distribuídos em diferentes regiões: fornecimento de matéria-prima, indústria (agregação de valor) e setores prestadores de serviços. A compra de bens intermediários e serviços de outras regiões causa o efeito transbordamento do multiplicador de produção e, conseqüentemente, de renda e emprego. Além disso, deve-se levar em consideração o local de consumo final do produto, importante fonte de receita (Imposto sobre Circulação de Mercadorias e Serviços) para os Estados.

\section{BIBLIOGRAFIA}

Guilhoto, J. J. M.; Hewings, G. J. D.; Sonis, M. Synergetic interctions between 2 Brasilian regions: an application of input-output linkages. 45 North American Meetings of the RSAI. Santa Fe, New Mexico, 11-14, nov. 1998. 
. Productive relations in the Northest and the rest of Brazil regions in 1992: decomposition \& synergy in input-output systems. Anais do XXVII Encontro Nacional de Economia, Belém, Pará, 7 a 10 de dezembro, p. 1437-1452, 1999.

Guilhoto, J. J. M. Decomposition \& synergy: a study of the interactions and dependence among the 5 Brasilian macro regions. Dublin, Irland: 39th European Congress of the ERSA/RSAI, 1999, 23p.

Guilhoto, J. J. M.; Moretto, A. C.; Rodrigues, R. L. Decomposition \& synergy: a study of the interactions and dependence among the 5 Brazilian macro regions. Economia Aplicada, v. 5, n. 2, p. 345-362, AbrilJunho 2001.

Guilhoto, J. J. M.; Sesso Filho, U. A. Estimação da matriz insumo-produto a partir de dados preliminares das contas nacionais. Economia Aplicada, v. 9, n. 2, p. 277-299, Abril-Junho 2005.

Instituto Brasileiro de Geografia e Estatística. Contas regionais do Brasil, 1999. Rio de Janeiro, 2001, $108 \mathrm{p}$.

Isard, W. Interregional and regional input-output analysis: a model of a space-economy. Review of Economics and Statistics, n. 33, p. 319-328, 1951.

Leontief, W. The structure of the American economy. Segunda Edição Ampliada. New York: Oxford University Press, 1951. 264p.

. Input-output economics. $2^{\underline{a}}$ ed. New York: Oxford University Press, 1986, p. 241-260.

Miyazawa, K. Input-output analysis and the structure of income distribution. Berlim: Springer-Verlag, 1976, 135p. (Mathematical economics-Lectures notes in economics and mathematical systems, 116)

Miller, R. E.; Blair, P. D. Input-output analysis: foundations and extensions. Englewood Cliffs: PrenticeHall, 1985, 464p.

Moretto, A. C. Relações intersetoriais e inter-regionais na economia paranaense em 1995.2000. 161p. Tese (Doutorado) - Escola Superior de Agronomia Luiz de Queiroz, Universidade de São Paulo, Piracicaba.

Round, J. I. Nonsurvey techniques: a critical review of the theory and the evidence. International Regional Science Review, v. 8, n. 3, p. 189-121, 1983.

Sonis, M.; Hewings, G. J. D. Error and sensitivity input-output analysis: a new approach. In: Miller, R. E.; Polenske, K. R.; Rose, A. Z. (eds.), Frontiers of input-output analysis. New York: Oxford University Press, 1989.

. Economic landscapes: multiplier product matrix analysis for multiregional input-output systems. Hitotsubashi Journal of Economics, 40, p. 59-74, 1999.

Sonis, M.; Hewings, G. J. D; Miyazawa, K. Synergetic interactions within the pair-wise hirarchy of economic linkges sub-systems. Hitotsubashi Journal of Economics, n. 38, p. 2-17, dez. 1997.

Souza, N. de J. Metodologia de obtenção das matrizes de insumo-produto dos estados da região sul, $1985 \mathrm{e}$ 1995. Porto Alegre: UFRGS, 1997. (Texto para discussão, 97/14). 15p. 